\title{
Manajeman Produksi Usaha Lampu Hias Kreasi Bamboo di Kabupaten Bangkalan Propinsi Jawa Timur
}

\author{
Buaddin Hasan \\ Program studi Pendidikan Matematika, STKIP PGRI Bangkalan \\ e-mail : buaddinhasan@stkippgri-bkl.ac.id
}

\begin{abstract}
ABSTRAK
Lampu hias merupakan salah satu ornamen yang menjadi penghias ruangan. Ornamen ini biasa dipajang di kamar tidur ataupun ruang keluarga. Pada umumnya ornamen ini terbuat dari bahan-bahan seperti kaca, kristal dari plastik, ataupun stainless steel. Adanya bambu yang melimpah di desa Jaddih Kecamatan Socah Kabupaten Bangkalan berhasil dimanfaatkan oleh pemuda setempat (Imam Syafii) menjadi kerajinan bambu ukir lampu hias. Meski tergolong baru, kerajinan tangan beraneka motif tersebut sangat diminati karena bentuknya yang cukup unik. Dalam rangka mengatasi permasalahan yang dihadapi masyarakat mitra, tim pengusul bekerjasama dengan mitra memanfaatkan bambu dengan memberikan berbagai pelatihan dan pendampingan dalam pengembangan Usaha Lampu Hias Kreasi Bamboo (Lapas Kriboo) dengan memanfaatkan IPTEK. Pelaksanaan program pengabdian ini dilakukan dengan 4 metode, pertama metode pendidikan masyarakat yaitu pelatihan dan pendampingan dalam memanfaatkan bambu dengan berbagai desain motif ukir menjadi lampu hias ukir, metode pelatihan ini merupakan upaya mendidik dan melatih mitra agar mampu memanfaatkan bambu sehingga menghasilkan kerajinan berupa lampu hias. Kedua, Metode Substitusi IPTEK yaitu memberikan gambaran cara memasarkan produk dan melakukan pendampingan sampai mitra mampu memasarkan produk dengan baik, pada tahap ini pengusul melakukan pendampingan kepada masyarakat agar mampu memanfaatkan media sosial dan media rekanan untuk memasarkan produk, serta melatih untuk dapat bermitra dengan toko-toko pusat oleh-oleh di Kabupaten Bangkalan. Hasil yang diperoleh dalam kegiatan pengabdian kepada masyarakat ini adalah peningkatan produksi dan motif ukir lampu hias mencapai $40 \%$ dari semula, hal ini berdampak pada peningkatan pendapatan mitra usaha.
\end{abstract}

Kata kunci : lampu; ukir, bambu

\begin{abstract}
Decorative lights are one of the ornaments that become a room decorator. These ornaments are usually displayed in the bedroom or family room. In general, these ornaments are made of materials such as glass, crystals from plastic, or stainless steel. The abundance of bamboo in Jaddih village, Socah Subdistrict, Bangkalan Regency was successfully utilized by the local youth (Imam Syafii) to become a bamboo craft carving for decorative lights. Although relatively new, these various motives are in great demand because of their unique shape. In order to overcome the problems faced by partner communities, the proposing
\end{abstract}


team collaborated with partners to use bamboo by providing various training and assistance in the development of the Bamboo Creative Lighting (Kriboo Lapas) business by utilizing science and technology. The implementation of this service program was carried out with 4 methods, firstly the method of public education, namely training and mentoring in utilizing bamboo with various designs of carved motifs into decorative carving lamps. Second, the Science and Technology Substitution Method is to provide an overview of how to market products and provide assistance until partners are able to market their products well, at this stage the proponents provide assistance to the community to be able to utilize social media and media partners to market products, and train to be able to partner souvenir shop in Bangkalan Regency. The results obtained in the community service activities were an increase in production and decorative lighting motifs reaching $40 \%$ from the beginning, this resulted in an increase in business partner income.

Keywords : lamp; carved; bamboo

\section{PENDAHULUAN}

Kondisi masyarakat di Desa Jaddih Kecamatan Socah Kabupaten Bangkalan lebih tergantung lahan pertanian yang kadang tidak sebanding dengan modal yang dikeluarkan. Namun pada hakikatnya banyak sumber daya alam berupa bambu yang belum mampu dimanfaatkan oleh masyarakat. Hal ini disebabkan karena tidak ada proses spesifik yang dilakukan oleh masyarakat dalam pemanfaatan sumber daya alam tersebut untuk meningkatkan nilai tambah ke level pasar lebih tinggi.

Pemberdayaan sumber daya manusia harus dilandasi dengan kondisi eksisting di masyarakat. Masyarakat yang mempunyai sumber daya alam yang melimpah terkadang tidak didukung dengan adanya pengetahuan dan keterampilan dalam pemamfaatan sumber daya alam tersebut. Untuk itu diperlukan upaya pemberdayaan masyarakat dihubungkan dengan konsep mandiri, partisipasi, jaringan kerja dan keadilan sebagai bentuk bekerjasama dengan masyarakat dalam rangka peningkatan kesejahteraan masyarakat.
Bambu adalah tanaman yang bisa tumbuh secara liar di berbagai daerah yang ada di Indonesia. Biasanya bambu tumbuh di hutan dan tempat yang jauh dari perkotaan, meskipun begitu bambu sangat mudah ditemukan karena tumbuhnya tidak membutuhkan perawatan. Bambu bisa tumbuh dengan subur di Indonesia karena iklim tropisnya cocok untuk jenis tanaman yang satu ini. Untuk bambu yang masih kecil saja sudah bisa dimakan dan menjadi lauk yang enak, sedangkan bambu yang sudah mulai tua bisa digunakan untuk membuat rumah penduduk, hingga kerajinan tangan yang bernilai jutaan. Meskipun kerajinan tangan dari bambu cukup sulit untuk dibuat, tetapi nilai jualnya dan nilai seni yang ada pada kerajinan tangan dari bambu ini membuat banyak orang tertarik untuk membuatnya.

Sumber daya alam yang dimiliki oleh masyarakat Desa Jaddih salah satunya adalah bambu. Di setiap kebun atau pinggiran rumah masyarakat di desa Jaddih notabene banyak pohon bambu yang belum dimanfaatkan oleh masyarakat setempat untuk menjadi 
produk yang bernilai ekonomis tinggi. Melihat kondisi yang seperti itu perlu adanya ide kreatif untuk mengubah bambu mejadi kerajianan yang bernilai tinggi.

Bahan baku utama lampu hias kreasi rumah ukir bambu adalah bambu. Bambu ditebang, kemudian diukur sesuai ukurannya, dan dilakukan proses perendaman kurang lebih 1 bulan agar tidak mudah pecah. Kemudian bambu diukir menggunakan mesin ukir. Pada proses finishing lampu hias, ukiran bambu ini dicat menggunakan vernish dan di pasang lampu beserta saklarnya. Lampu hias ukuran kecil dijual dengan harga antar 100-150 ribu, sedangkan lampu hias ukuran $40 \mathrm{~cm}$ dijual antara 200-250 ribu.

Berdasarkan hasil wawancara pengusul dengan mitra (pemilih Usaha Lampu hias) mengatakan bahwa produksi lampu hiasnya bisa dikembangkan seperti halnya produk lainya. Untuk mencapai hal tersebut, perlu adanya keterampilan dalam pengembangan desain motif ukir dan kesesuaian dengan tema yang sedang trend, contohnya ; pada saat pagelaran piala dunia, permintaan lampu hias tropi piala dunia sangat banyak. Selain itu juga perlu pemanfaatan IPTEK untuk memudahkan dalam proses produksi, diantaranya mesin cat, alat pres packing. Kemudian pemanfatan internet untuk mencari desain yang unik dan sesuai. Dan juga perlu desain kemasan yang menarik untuk menarik minat para pembeli. Imam optimis jika kualitasnya ditingkatkan, apalagi ada peningkatan perbaikan dalam kemasan dan proses pemasaran yang lebih bersaing, maka nilai jualnya juga akan semakin meningkat.

Perlu adanya pemberdayaan masyarakat untuk memanfaatkan bambu menjadi barang yang bernilai ekonomi tinggi. Dalam hal ini pemberdayaan dilakukan dengan memberikan peluang usaha yang lebih baik untuk mengkreasikan bambu menjadi lampu hias yang layak jual, sehingga dengan sendirinya mereka dapat meningkatkan nilai tambah kesejahteraannya.

Adanya bambu yang melimpah di desa Jaddih Kecamatan Socah Kabupaten Bangkalan berhasil dimanfaatkan oleh pemuda setempat (Imam Syafii) menjadi kerajinan bambu ukir lampu hias. Meski tergolong baru, kerajinan tangan beraneka motif tersebut sangat diminati karena bentuknya yang cukup unik.

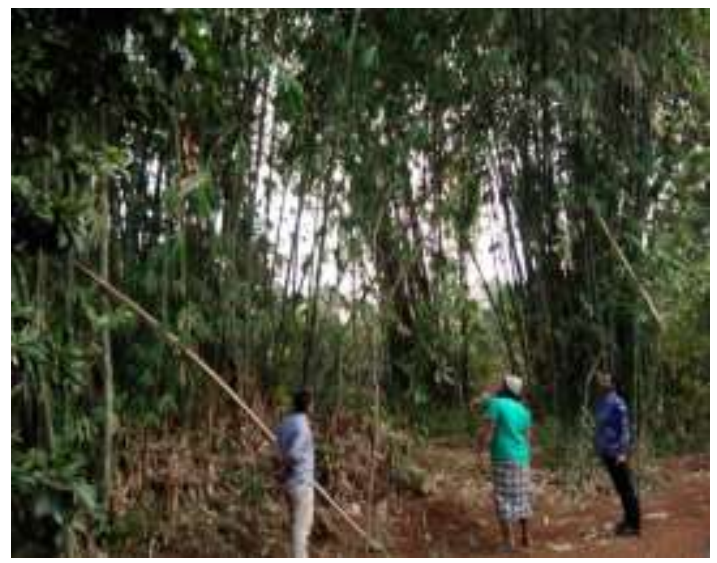

Gambar 1. Potensi Bambu

Kabupaten Bangkalan terus berupaya mengembangkan dunia pariwisata dan UMKM, guna peningkatan kesejahteraan masyarakat, ditambah pula ketersediaan bahan baku utama bambu yang melimpah di daerah Jaddih Kabupaten Bangkalan, sehingga program PKM ini diharapkan dapat meberikan wawasan dan pengetahuan baru kepada pemuda Kabupaten Bangkalan dalam memanfaatkan bambu menjadi kerajinan berupa lampu hias ukir sehingga berdampak pada peningkatan pendapatan 
perkapita masyarakat di desa Jaddih Kabupaten Bangkalan

\section{Aspek produksi}

Proses mengukir bambu menjadi lampu hias yang unik tidak terlalu sulit dan murah, memungkinkan masyarakat atau pemuda di Kabupaten Bangkalan untuk mengembangkan usahanya. Hal ini didukung adanya:

- Ketersediaan bahan utama yaitu bambu, karena sebagian besar daerah di desa Jaddih Kecamatan Socah Kabupaten Bangkalan tumbuh tanaman bambu.

- Banyak pemuda yang tidak bekerja sehingga bisa diberdayakan dan dilatih untuk dapat memanfaatkan bambu menjadi kerajinan yang mempunyai nilai ekonomi, salah satunya lampu hias ukir bambu

- Biaya produksi yang murah, karena tersedianya bahan baku yang melimpah.

\section{Aspek Manajemen usaha}

Untuk menjamin ketercapaian pengembangan produksi kerajinan lampu kreasi bambu. Pengusul bersama dengan mitra menyusun manajemen usaha dengan melihat beberapa aspek, diantaranya;

- Aspek kualitas, dalam produksi lampu hias kreasi bambu mitra selalu konsisten menjaga kualitas produk, sehingga dapat menjaga kepercayaan pembeli dan bisa laku di pasaran. Menurut Aryani, D., \& Rosinta, F. (2011) bahwa terdapat pengaruh yang kuat dan positif antara kualitas layanan terhadap loyalitas pelanggan [1]. Kemudian Menurut Ghanimata, F., \& Kamal, M. (2012) kualitas produk dan lokasi terbukti secara positif dan signifikan mempengaruhi konsumen dalam keputusan pembelian suatu barang [2].

- Aspek packing, proses pengemasan produk didesain semenarik mungkin agar dapat menarik minat pembeli. Hariadi, D. (2015) yang menyatakan bahwa packaging (kemasan) serta icon produk dapat mempengaruhi konsumen dalam keputusan pembelian suatu barang [3].

- Aspek pemasaran, lokasi kabupaten Bangkalan yang strategis dengan adanya jembatan suramadu menjadikan proses pemasaran lampu hias kreasi rumah ukir bambu yang sangat menjanjikan, proses pemasaran produk dapat dilakungan melalui:

Mendirikan stand rumahan, (2) distribusi ke toko tempat wisata di Bangkalan, (3) pemasaran melalui media sosial (Blog rumah ukir bambu, Google, FB, BBM, WA, Instagram).

- Aspek harga, harga penjualan lampu hias kreasi rumah ukir bambu disesuaikan dengan harga dipasaran sehingga mampu bersaing.

\section{Sumber daya}

Dalam mendukung keberlangsungan program produksi lampu hias perlu adanya sumber daya yang memadai. Sumber daya manusia, produksi lampu hias tidak memerlukan keahlian khusus, sehingga pemberdayaan pemuda di Desa Jaddih Kabupaten Bangkalan sangat memungkinkan untuk direkrut menjadi tenaga kerja, disamping itu proses produksi tidak telalu sulit sehingga pengusul dapat memberikan pelatihan dan pendampingan dalam produksi, packing, 
terutama dalam proses manajemen dan pemasaran. Menurut Hasan, B. dan Rizkiana, A (2018) sumber daya manusia yang terampil, tekun dan ulet berpengaruh terhadap hasil produksi [4].

\section{Sumber daya alam}

Desa Jaddih Kecamatan Socah Kabupaten Bangkalan sebagaian besar merupakan dataran dengan suhu yang panas, sehingga tanaman bambu banyak tumbuh di daerah tersebut.

\section{METODE KEGIATAN}

Dalam $\begin{array}{lr}\text { rangka } & \text { menjamin } \\ \text { kesuksesan pelaksanaan } & \text { program } \\ \text { pengabdian ini, metode yang } & \text { dilakukan } \\ \text { dibagi dalam } 3 \text { tahapan, yaitu: }\end{array}$

\section{a. Tahap Persiapan}

Pada tahapan ini tim pengusul melakukan diskusi bersama mitra membahas persiapan yang diperlukan untuk memulai pelaksanaan program PKM. Pengusul menyusun jadwal pelatihan dan coba mendesain dan membuat alat yang diperlukan.

\section{b. Tahap Pelaksanaan}

Pada tahap pelaksanan, pengusul bersama mitra melakukan langkah metode yang akan diterapkan, antara lain;

1. Metode Pendidikan Masyarakat

Yaitu, memberikan pelatihan dan pendampingan dalam memanfaatkan bambu menjadi lampu hias. Serta berbagai motif ukir.

2. Metode Substitusi IPTEK

Yaitu memberikan gambaran cara memasarkan produk dan melakukan pendampingan sampai mitra mampu memasarkan produk dengan baik sebagai bentuk implementasi cobenefit. Dalam metode ini pengusul melakukan pendampingan kepada mitra agar mampu memanfaatkan media sosial dan media rekanan untuk memasarkan produk, serta melatih untuk dapat bermitra dengan toko-toko pusat oleh-oleh di Kabupaten Bangkalan. IPTEK yang dimanfaatkan sebagai media pemasaran, misalnya; media facebook. WA, BBM, IG dan sebagainya. Adanya pemasaran yang sesuai dengan perkembangan jaman, misalnya media online, pemasaran produk semakin berkembang yang berdampak pada peningkatan hasil usaha [5].

\section{c. Tahap Penyelesaian}

Pada tahapan ini, Tim Pengusul akan fokus pada proses penyusunan laporan dan penulisan artikel publikasi. Untuk publikasi hasil program berupa artikel yang akan diterbitkan pada Jurnal Nasional Pengabdian, dan video kegiatan. Tahapan ini dilakukan setelah pelaksanaan program PKM

\section{KARYA UTAMA}

Dalam pelaksanaan pengabdian kepada masyarakat ini, hasil yang dikembangkan berupa lampu hias kreasi bambu, bahan baku utama dalam program pengabdian ini adalah bambu.

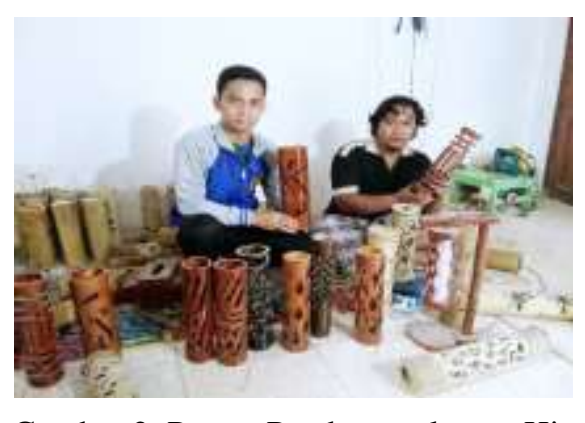

Gambar 2. Proses Pembuatan lampu Hias 
Dalam produksi lampu hias mitra dibantu oleh beberapa teman kerja yang mayoritas adalah pemuda yang ada di desa jaddih barat. Dalam setiap bulan usaha lampu kreasi bambu ini mampu memproduksi 10-15 unit lampu hias yang dijual berdasarkan pesanan.

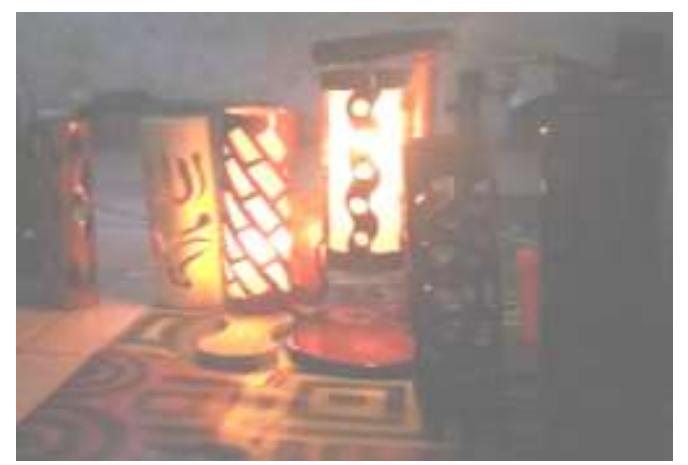

Gambar 3. Hasil Produksi Lampu Hias

\section{ULASAN KARYA}

Hasil produksi usaha lampu hias kreasi bambu ini mempunyai keunggulan tersendiri dibanding dengan lampu hias yang lain,

1. Lampu hias kreasi bambu ini tidak mudah pecah karena proses pembuatannya menggunakan teknik perendaman selama kurang lebih 1 bulan sampai akhirnya bambu siap diukir

2. Cat halus dan tidak mudah luntur, karena dalam proses finishing pemilik usaha ini menggunakan metode oven dalam pengeringan cat.

\section{DAMPAK DAN MANFAAT KEGIATAN}

Adanya program pengabdian kepada masyarakat ini memberikan danpak dan manfaat kepada mitra yang sangat membantu dalam proses pengembangan produksi lampu hias, adapun dampak yang dirasakaan secara langsung oleh mitra antara lain:

1. Mitra dalam mengembangkan motive ukir lampu hias,

2. Mitra dapat melakukan pembukuan dalam pelaporan keuangan usaha, meskipun hanya pembukauan sederhana

3. Mitra dapat memasarkan produk dengan baik.

\section{KESIMPULAN}

Dari pelaksanaan program pengabdian kepada masyarakat ini dapat disimpulkan :

1. Adanya peningkatan hasil produksi lampu hias kreasi bambu sebeasar $40 \%$ dari produksi semula.

2. Adanya variasi motif ukir yang semakin banyak, antara lain: motif batik, motif burung, motif kotak, motif lingkaran, dan motif sesuai dengan karakter pesanan.

3. Adanya peningkatan pendapatan mencapai $30 \%$ persen dari hasil sebelumnya, hal ini terjadi karena adanya perbaikan sistem pemasaran melalui online dan toko rekanan.

\section{DAFTAR PUSTAKA}

[1]. Aryani, D., \& Rosinta, F. (2011). Pengaruh Kualitas Layanan terhadap Kepuasan Pelanggan dalam Membentuk Loyalitas Pelanggan. Bisnis \& Birokrasi : Jurnal Ilmu Administrasi dan Organisasi, 17 (2).

[2]. Ghanimata, F., \& Kamal, M. (2012). Analisis Pengaruh Harga, Kualitas Produk, dan Lokasi 
Terhadap Keputusan Pembelian (Studi Pada Pembeli Produk Bandeng Juwana Elrina Semarang). Doctoral dissertation, Fakultas Ekonomika dan Bisnis.

[3]. Hariadi, D. (2015). Pengaruh produk, harga, promosi dan distribusi Terhadap keputusan pembelian konsumen Pada produk projector microvision. Jurnal Ilmu \& Riset Manajemen, 1(8).

[4]. Hasan, B. \& Rizkiana. A. (2018). Varian Produksi, Manajemen Keuangan dan Pemasaran Usaha Mikro Kerupuk Kerang Madurasa di Kabupaten Bangkalan. International Journal of Community Service Learning. Vol. 2 No. 3

[5]. Hasan, B., \& Rizkiana, A. (2018). Pengembangan Usaha Mikro Kerupuk Kerang Madurasa (Produk Madura Citarasa Nusantara) di Kabupaten Bangkalan. Seminar Nasional Hasil Pengabdian Kepada Masyarakat (Vol. 2, No. 1, pp. 3741). 